\title{
New insights into the relationship between draw solution chemistry and trace organic rejection by forward osmosis
}

\author{
Lei Zheng ${ }^{a}$, William E. Price ${ }^{b}$, James McDonald ${ }^{c}$, Stuart J. Khan ${ }^{c}$, Takahiro Fujioka ${ }^{d}$, Long D. Nghiem ${ }^{\text {a, e, * }}$ \\ ${ }^{a}$ Center for Technology in Water and Wastewater, University of Technology Sydney, NSW, 2007, Australia \\ ${ }^{\mathrm{b}}$ Strategic Water Infrastructure Laboratory, University of Wollongong, NSW, 2522, Australia \\ ${ }^{c}$ School of Civil and Environmental Engineering, University of New South Wales, NSW, 2052, Australia \\ ${ }^{\mathrm{d}}$ Water and Environmental Engineering, Graduate School of Engineering, Nagasaki University, 1-14 Bunkyo-manchi, Nagasaki, 852-8521, Japan \\ ${ }^{\text {e }}$ NTT Institute of Hi-Technology, Nguyen Tat Thanh University, Ho Chi Minh City, Viet Nam
}

\section{A R T I C L E I N F O}

\section{Keywords:}

Forward osmosis

Membrane fouling

Trace organic contaminants

Wastewater

Reverse salt flux

\begin{abstract}
A B S T R A C T
This study elucidates the impact of draw solution chemistry (in terms of $\mathrm{pH}$ and draw solute species) and membrane fouling on water flux and the rejection of trace organic contaminants by forward osmosis. The results show that draw solution chemistry could induce a notable impact on both water flux and TrOCs rejection. In addition, the impact was further influenced by membrane fouling. The reverse flux of proton (or hydroxyl) could alter the feed solution $\mathrm{pH}$, which governed the separation of ionisable TrOCs. In addition, charged compounds generally exhibited higher rejection than neutral ones by the clean membrane. Electrostatic interaction, rather than size exclusion, was therefore the dominant rejection mechanism for most compounds. There was also a weak correlation between rejection and molecular sizes of the $43 \mathrm{TrOCs}$. Compared with $\mathrm{Na}^{+}, \mathrm{Li}^{+}$with a larger hydrated radius showed a significant lower reverse salt flux, resulting in a lower ionic strength and therefore a stronger electrostatic interaction. A fouling cake layer consisted of low molecular weight neutral organics could also affect TrOC rejection due to pore blockage and cake-enhanced concentration polarisation.
\end{abstract}

\section{Introduction}

Using osmotic pressure as the driving force for water transportation across the semi-permeable membrane, forward osmosis (FO) has the potential for several new separation applications. Compared to pressure-driven membrane processes, FO is less susceptible to fouling and requires significantly less energy, particularly when draw solution regeneration is not required [1,2]. As a novel membrane process, FO has been investigated for the treatment of challenging wastewater [3] and a range of innovative applications including resource recovery [4,5], hypersaline desalination $[6,7]$, and sludge thickening $[8,9]$.

The ubiquitous occurrence of trace organic contaminants (TrOCs) in municipal wastewater has been a topic of major scientific and public concern in the past decade [10]. These TrOCs negatively affect human health and the ecosystem even at a very low concentration. Some of them are specifically designed to be persistent in the environment [11]. Membrane processes, such as nanofiltration (NF) [12], reverse osmosis (RO) [13], membrane distillation [14], membrane bioreactor [15] and forward osmosis [16-19] have been widely explored for removing TrOCs from wastewater. Given the similarity in membrane structure between FO and NF/RO, recent research has shown that TrOCs rejection by FO may also be governed by the steric hindrance, hydrophobic adsorption and electrostatic interaction [20]. Thus, physiochemical properties of TrOCs, membrane properties and membrane fouling have been reported to play significant roles in governing TrOCs rejection by FO $[21,22]$.

Feed solution chemistry can influence both ionization state of TrOCs and membrane surface, and therefore TrOCs rejection by FO has been extensively investigated in the literature. Jin et al. [23], compared the rejection of four TrOCs (diclofenac, carbamazepine, ibuprofen and naproxen) by cellulose triacetate (CTA) and thin film composite (TFC) FO membranes. They reported stable rejections for four TrOCs by TFC membrane regardless of any variation in feed solution $\mathrm{pH}$ [23]. However, their observed rejections by CTA membranes varied considerably due to variable chemical speciation as a function of feed $\mathrm{pH}$. Xie et al. [24], compared the rejection of two pharmaceuticals (carbamazepine and sulfamethoxazole) by the CTA FO membrane as a

\footnotetext{
* Corresponding author. Center for Technology in Water and Wastewater, University of Technology Sydney, NSW, 2007, Australia.

Email address: Duclong.Nghiem@uts.edu.au (L.D. Nghiem)
} 
function of feed $\mathrm{pH}$. Electrostatic repulsion and steric hindrance both exhibited effects on rejection in relation to the speciation of compounds. In agreement with previous findings by Xie et al. [24], Zhu et al. [25], observed that the electrostatic repulsion was the dominating mechanism for the rejection of negatively charged compounds (cyclohexane carboxylic acid, 1-adamantaneacetic acid) since the CTA membrane became more negatively charged when $\mathrm{pH}$ was increased.

Unlike the NF/RO process in which solute and solvent transport can only occur in one direction from the feed to the permeate side, solute transport in FO is bidirectional. In the FO process, as water is transported from the feed to the draw solution under an osmotic gradient, due to engineering defects, some substances (e.g. draw solutes, protons or hydroxyl ions) can also be transported in the opposite direction from the draw to the feed solution. This phenomenon is often referred to as 'reverse salt flux'.

Reverse salt flux and draw solution chemistry are important factors governing FO performance (in terms of solute rejection and water flux) but to date they have been largely overlooked in the literature. Indeed, several recent studies have highlighted the significance of draw solution chemistry on solute rejection by FO (Table 1). Wang et al. [29], demonstrated a significant increase in boron rejection by FO when using an alkaline draw solution. They ascribed the observed increase in boron rejection to the interaction between their draw and feed solutions whereby there was an increase in hydroxyl ions near the membrane surface on the feed side. This lead to the protonation of boric acid and subsequently increase of boric acid rejection by charge repulsion [29]. Xie et al. [26], observed that the extent of forward diffusion of TrOCs was related to the reverse diffusion of draw solutes. They reported that the highest rejection occurred with highest reverse diffusion of draw solutes [26]. Despite these recent and dedicated studies,

Table 1

Effect of draw solution chemistry on FO performance.

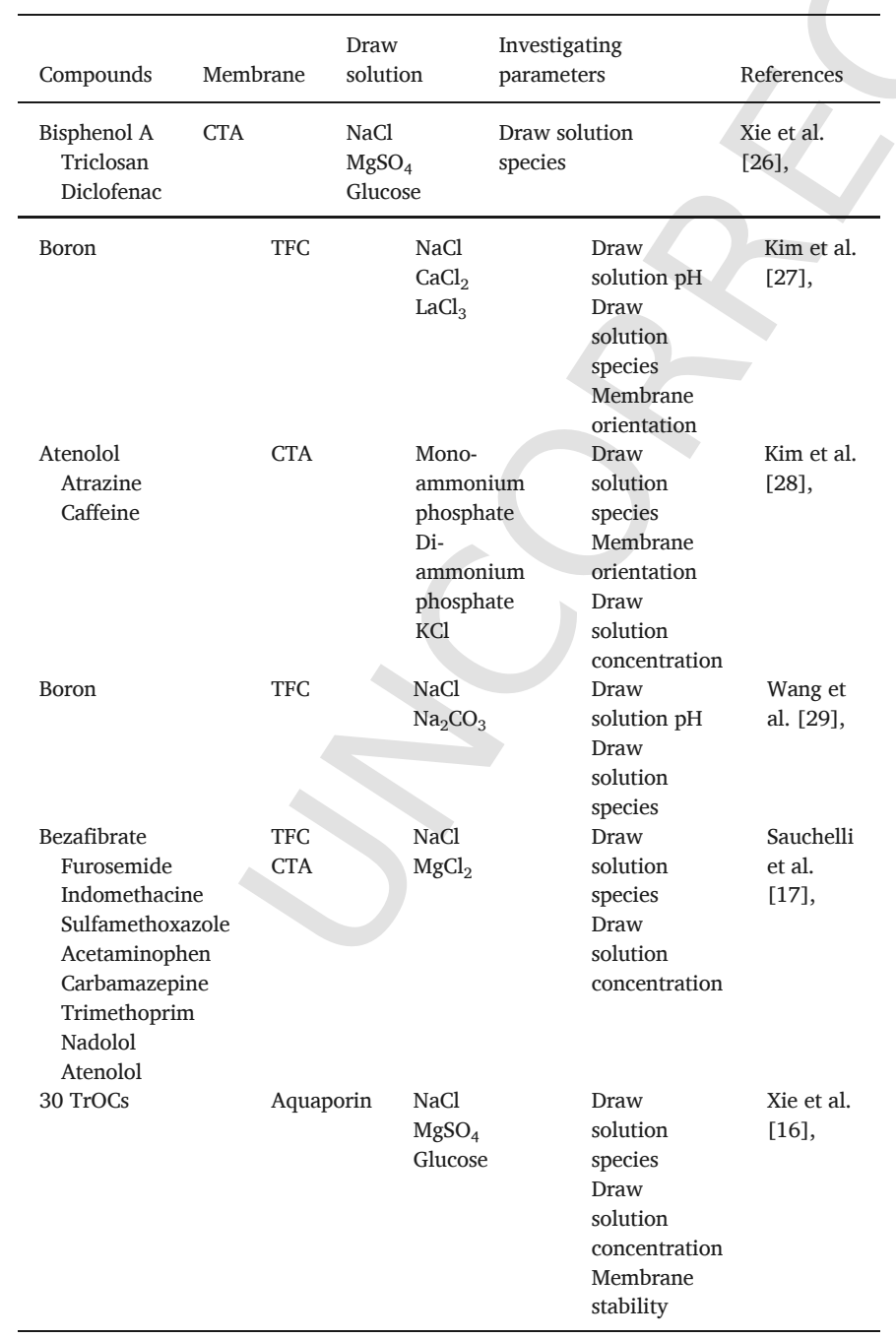

to date, little is known about the role of draw solution chemistry especially $\mathrm{pH}$ and draw solute species on the rejection of TrOCs by FO.

This study aims to elucidate the impact of draw solution chemistry on the rejection of TrOCs by FO. In addition to the impact of reverse salt flux on TrOCs rejection, which has been investigated in the few previous studies, the current work also focuses on the interplay between draw solution $\mathrm{pH}$ and species, membrane fouling, and water flux to generate new insights into the FO performance.

\section{Material and methods}

\subsection{Materials and trace organic contaminants}

A flat-sheet TFC-FO membrane from Porifera (Hayward, CA, USA) was used in this study. According to the manufacturer, the operational $\mathrm{pH}$ range of this membrane is from $\mathrm{pH} 2$ to 13. Both layers of the membrane are negatively charged above $\mathrm{pH} 4$ and become more negative as $\mathrm{pH}$ is increased.

To better contrast the draw solute hydrated size (thus the reverse salt flux) on FO performance, in addition to sodium chloride ( $\mathrm{NaCl})$, which has been the most widely used draw solute in the literature, lithium chloride ( $\mathrm{LiCl}$ ) was also used in this study. $\mathrm{LiCl}$ and $\mathrm{NaCl}$ were provided from Chem-Supply (SA, Australia). Sodium acetate ( $\mathrm{NaOAc}$ ), acetic acid (HOAc), sodium dihydrogen phosphate $\left(\mathrm{NaH}_{2} \mathrm{PO}_{4}\right)$, and disodium hydrogen phosphate $\left(\mathrm{Na}_{2} \mathrm{HPO}_{4}\right)$ from VWR (QLD, Australia) were used in buffer solutions. Deionized (DI) water was used to prepare the solution for this study. All chemicals were analytical grade. Municipal sewage was collected after primary sedimentation from a wastewater treatment plant in New South Wales, Australia. Key parameters of this sewage are summarized in Table 2.

As the representatives of widespread TrOCs from four categories (pesticides, pharmaceuticals, personal care products and industrial chemicals) in raw sewage, 43 TrOCs were selected in this study (Supplementary Data Table S1). A stock solution of all TrOCs was prepared in pure methanol at a concentration of $20 \mathrm{mg} / \mathrm{L}$ each on a monthly basis and stored at $-18^{\circ} \mathrm{C}$.

\subsection{Experimental system and protocol}

All experiments were performed using a bench scale FO system (Fig. 1). The membrane cell has two identical and symmetrical plastic flow chambers with length $10 \mathrm{~cm}$, width $5 \mathrm{~cm}$ and height $0.2 \mathrm{~cm}$. The effective area of membrane is approximately $44.6 \mathrm{~cm}^{2}$.

Unless otherwise stated, the draw solutions were buffered at $\mathrm{pH}$ 4.6 by using $\mathrm{NaOAc} / \mathrm{HOAc}(0.7 \mathrm{M} / 0.1 \mathrm{M})$; at $\mathrm{pH} 6.8$ by using $\mathrm{NaH}_{2} \mathrm{PO}_{4} / \mathrm{Na}_{2} \mathrm{HPO}_{4} \quad(0.1 \mathrm{M} / 0.48 \mathrm{M})$; at $\mathrm{pH} \quad 8.0$ by using $\mathrm{NaH}_{2} \mathrm{PO}_{4} / \mathrm{Na}_{2} \mathrm{HPO}_{4}(0.1 \mathrm{M} / 0.76 \mathrm{M})$. $\mathrm{NaCl}$ or LiCl was then added to the buffer solution to obtain a draw solution of $0.5 \mathrm{M}$. The draw solution volume was $0.5 \mathrm{~L}$. The feed solution (DI water or municipal sewage) volume was $2 \mathrm{~L}$.

The system was operated in the co-current FO configuration (active layer facing feed solution) with a cross-flow rate of $1.0 \mathrm{~L} / \mathrm{min}$ (corresponding to a cross-flow velocity $19.8 \mathrm{~cm} / \mathrm{s}$ ). The draw solution reservoir was placed on a digital balance (Mettler-Toledo Inc., Hightstown,

Table 2

Characteristics of primary treated municipal sewage.

\begin{tabular}{ll}
\hline Parameter & Value \\
\hline $\mathrm{pH}$ & $7.2-7.3$ \\
$\mathrm{COD}$ & $692.6 \mathrm{mg} / \mathrm{L}$ \\
$\mathrm{TOC}$ & $114.9 \mathrm{mg} / \mathrm{L}$ \\
TSS & $166.3 \mathrm{mg} / \mathrm{L}$ \\
Conductivity & $3525 \mu \mathrm{S} / \mathrm{cm}$ \\
\hline
\end{tabular}




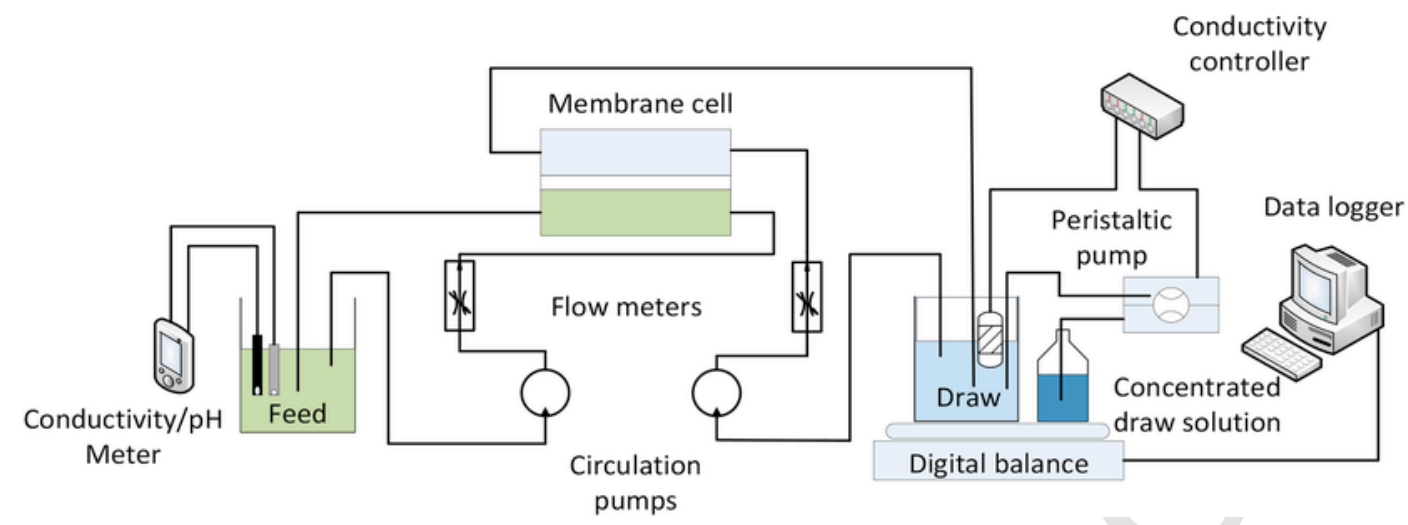

Fig. 1. Schematic diagram of the bench-scale forward osmosis system.

NJ) and weight change was recorded every $5 \mathrm{~min}$ by a computer. In order to diminish the weight interference between two reservoirs, the concentrated draw solution reservoir $(5 \mathrm{M} \mathrm{NaCl}$ or $\mathrm{LiCl}$ ) was placed on the same digital balance where draw solution was placed. The concentration of draw solution was monitored and maintained by a conductivity probe (Cole-Parmer, Vernon Hills, IL) connected with a peristaltic pump (control accuracy was $\pm 0.1 \mathrm{mS} / \mathrm{cm}$ ).

All experiments were conducted until 50\% water recovery has been achieved (i.e. $1 \mathrm{~L}$ water from the feed had permeated through the membrane to draw solution). The feed solutions were prepared by spiking 43 TrOCs into the DI water or municipal sewage to generate a concentration of $10 \mu \mathrm{g} / \mathrm{L}$ of each TrOCs (ignoring initial amount of TrOCs in municipal sewage). Feed and draw solution samples $(500 \mathrm{~mL}$ each) were taken at the beginning and end of each experiment for the analysis. Conductivity, $\mathrm{pH}$ of feed and draw solutions were monitored by an Orion 4 Star plus conductivity meter (Thermo Fisher Scientific, Waltham, MA) at specific time intervals. All FO experiments were conducted in duplicate. Water flux, $J_{w}$, was calculated as:

$J_{w}=\frac{M_{t}-M_{t-5}}{\Delta t \times A \times \rho_{\text {water }}}$

where $M_{t}$ and $M_{t-5}$ are the weights of draw solution at time $t$ min and $t-5$ min, respectively. $A$ is the effective membrane area; $\rho_{\text {water }}$ is the density of water; $\Delta t$ is $5 \mathrm{~min}$.

The reverse salt flux, $J_{s}$, was calculated by a mass balance calculation as:

$J_{s}=\frac{\left(C_{t} V_{\text {feed, },}-C_{0} V_{\text {feed }, 0}\right)}{A t}$

$V_{\text {feed }, t}=V_{\text {feed }, 0}-\Delta V_{p, t}$

where $C_{0}$ and $C_{t}$ are the concentration of the draw solute in the feed at the beginning and corresponding time $t$ of the experiment, respectively; $V_{\text {feed, } 0}$ and $V_{\text {feed, } t}$ are the volumes of the feed at the beginning and corresponding time $\mathrm{t}$ of the experiment; $\Delta V_{p, t}$ is the volume of permeate at time $t$.

The reverse salt flux selectivity (RSFS) was calculated as:

$R S F S=\frac{J_{w}}{J_{s}}$

Water recovery, $R_{w}$, or the water extraction rate of the FO experiment was calculated as:

$R_{w}=\frac{A \int_{0}^{T} J_{w} d_{t}}{V_{\text {feed }, 0}}$

\subsection{Analytical methods}

\subsubsection{Membrane morphology analysis}

Membrane samples were coated by a Quorum-SC7620 Mini Sputter Coater (Quorum Technologies, UK) prior to the surface morphology analysis. Each sample was investigated by a scanning electron microscope (SEM) (Phenom-ProX, Thermo Fisher, USA) in the detector mode for backscattered electrons with an operating voltage of $10 \mathrm{kV}$ and an operating pressure of $1 \mathrm{~Pa}$. Elemental analysis was conducted by an energy dispersive X-ray spectroscopy (EDX).

\subsubsection{Municipal sewage characterization}

The $\mathrm{pH}$ and conductivity of municipal sewage were measured by the $\mathrm{pH}$ and conductivity meter. Total suspended solids (TSS) was measured according to the standard method [30]. Chemical oxygen demand (COD) was measured following the US-EPA Method 8000 using high range COD vials (HACH, Colorado, USA). Total organic carbon (TOC) was measured by a VCSH TOC analyzer (Shimadzu, Kyoto, Japan).

Molecular weight distribution of municipal sewage was determined by liquid chromatography with organic carbon detection (LC - OCD) (Model 8, DOC - Labor, Karlsruhe, Germany). The feed samples were filtered through $0.7 \mu \mathrm{m}$ pore size glass microfiber filter paper prior to analysis. This method is described elsewhere [31]. Customized software (ChromCALC, DOC - LABOR, Karlsruhe, Germany) was used to acquire and process data.

\subsubsection{Trace organic contaminant analysis}

The analysis of TrOCs followed the method developed by Tadkaew et al., [32]. In brief this was carried out in three parts: solid phase extraction (SPE), liquid chromatography, and quantitative measurement by tandem mass spectrometry with electrospray ionization. Each sample was spiked with a surrogate (50 ng) of 43 isotopically labelled standards for method recovery and detection level determination. A $1 \mu \mathrm{m}$ pore size glass microfiber filter paper followed by $0.7 \mu \mathrm{m}$ one was used to treat municipal sewage feed samples for subsequent SPE. All liquid samples were loaded onto the preconditioned Oasis HLB cartridges (Waters, Millford, MA, USA) for TrOCs extraction. The precondition method followed the order: $5 \mathrm{~mL}$ methyl tert-butyl ether, $5 \mathrm{~mL}$ methanol, and $2 \times 5 \mathrm{~mL}$ Milli-Q water at the flow rate of approximate $15 \mathrm{~mL} / \mathrm{min}$. The SPE procedure was conducted slowly at a rate about $15-20 \mathrm{drop} / \mathrm{min}$. The cartridges were rinsed twice with Milli-Q water after SPE and were dried by nitrogen gas.

Two solutions: methanol $(5 \mathrm{~mL})$, mixture of methanol and methyl tert-butyl ether $(1: 9, \mathrm{v} / \mathrm{v}, 5 \mathrm{~mL})$ were used to extract TrOCs from loaded cartridges. Then, the extracted TrOCs were firstly concentrated to $100 \mu \mathrm{L}$ followed by diluting to $1 \mathrm{~mL}$ with methanol. The diluted ex- 
tracts were analyzed by a high performance liquid chromatography (Agilent 1200 series, Palo Alto, CA, USA) with a Luna C18 (2) column (Phenomenex, Torrence CA, USA) for TrOCs separation. Selected TrOCs were identified and quantified by an isotope dilution method using a triple quadrupole mass spectrometer (API 4000, Applied Biosystems, Foster City, CA, USA) equipped with a turbo $\mathrm{V}$ ion source that was employed in both positive and negative electro - spray modes. This method had a limit of quantification of $20 \mathrm{ng} / \mathrm{L}$ for bisphenol A, 10 ng/L for caffeine, triclocarban and diuron, and 5ng/L for all other TrOCs [33].

TrOC rejection, $R$, was calculated as:

$R=\left(1-\frac{D F \times C_{T r O C, d}}{C_{T r O C, f}}\right) \times 100 \%$

where $C_{\text {TrOC,d }}$ is the concentration of each TrOC in the draw solution, $C_{\text {TrOC, }}$ is the concentration of each TrOC in the feed solution, and DF is the dilution factor and defined as:

$D F=\frac{V_{d}}{V_{p}}$

where $V_{d}$ is the final volume of the draw solution and $V_{p}$ is the total volume of permeate.

\section{Results and discussion}

\subsection{Impact of draw solution chemistry on water flux}

The draw solution $\mathrm{pH}$ asserted a small but nevertheless discernible impact on water flux (Fig. 2). At a draw solution of $\mathrm{pH} 4.8$, the flux decline was most noticeable when DI water was used as the feed solution, corresponding to the longest time to achieve $50 \%$ water recovery. This was followed by draw solutions at $\mathrm{pH} 6.7$ and $\mathrm{pH} 8.0$ (Fig. 2a-c). It is
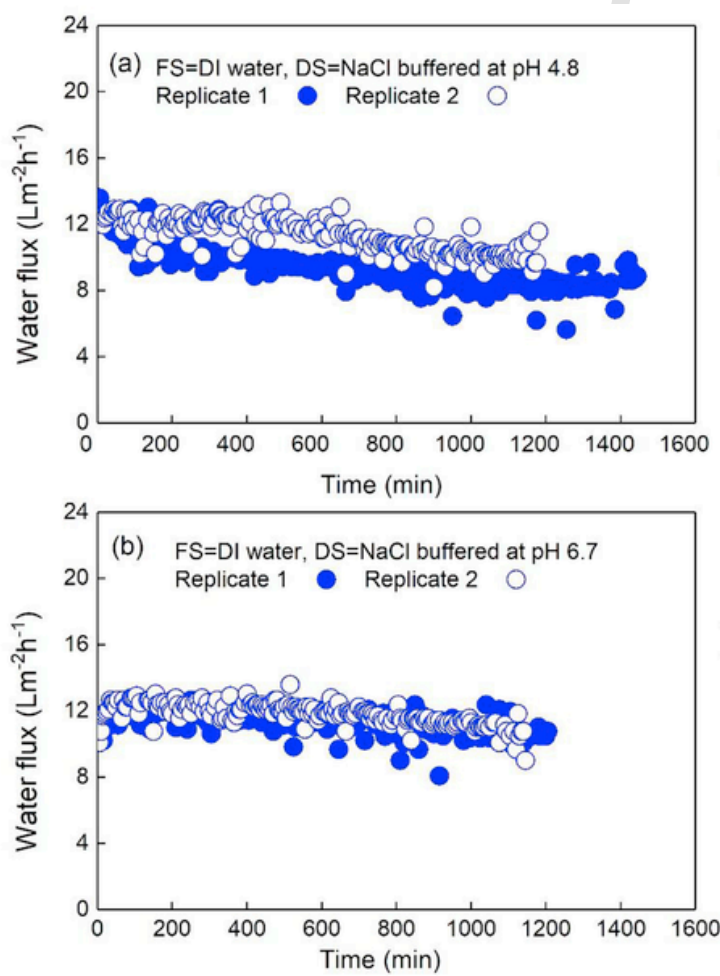

noted that the DI feed water was at pH 6.4. Results in Fig. 2a-c could be attributed to the difference in $\mathrm{pH}$ between the draw and feed solution, leading to the transfer of proton ions into the feed solution. Since $\mathrm{pH}$ is a logarithmic function of proton concentration, the concentration gradient for the proton transfer between solutions at $\mathrm{pH} 4.8$ and $\mathrm{pH} 6.4$ (feed $\mathrm{pH}$ ) is several orders of magnitude higher than between those at $\mathrm{pH} 6.7$ and $\mathrm{pH}$ 6.4. On the other hand, there was also the back diffusion of $\mathrm{Na}^{+}$ from the draw to the feed solution. The transport of both proton and $\mathrm{Na}^{+}$was coupled with the transport of a counter ion, $\mathrm{Cl}^{-}$in this case, for electro-neutrality. Thus, a high concentration of proton in the draw solution can interfere with the transport of $\mathrm{Na}^{+}$at $\mathrm{pH} 4.8$, leading to a smaller overall osmotic gradient across the membrane active layer, and hence, lower water flux when compared to pH 6.7 (Fig. 2a and b). Indeed, the lowest $\mathrm{NaCl}$ reverse salt flux was observed with draw solution at pH 4.8 (Fig. S1). The interplays among the transport of key solutes at different draw solution $\mathrm{pH}$ are schematically presented in Fig. 3.

$\mathrm{NaCl}$ and $\mathrm{LiCl}$ as the draw solutes showed different flux performance despite their similar osmotic potentials based on the van't Hoff theory (Fig. 2d and Fig. S2). At the same $\mathrm{pH}$ and DS molar concentration, $\mathrm{LiCl}$ resulted in a lower water flux compared to $\mathrm{NaCl}$ corresponding to a longer operation time to achieve $50 \%$ water recovery. The effect of external concentration polarisation can be mitigated by maintaining a crossflow $(19.8 \mathrm{~cm} / \mathrm{s})$ over the membrane surface [34]. Thus, the observed differences in water flux profile at the same draw solution concentration (thus osmotic potential) in Fig. 3 can be attributed to the difference in hydrated radius between two draw solutes and the internal concentration polarisation (ICP) effect. In this study, the active layer was against the feed solution. Thus, within the porous supporting layer, the draw solution is diluted by the water flux, which is referred to as the dilutive ICP on the permeate side. With a larger hydrated radius and lower diffusivity, $\mathrm{Li}^{+}$potentially leads to a more severe dilutive ICP (Fig. 3), and thus a lower water flux as observed in Fig. 2d.
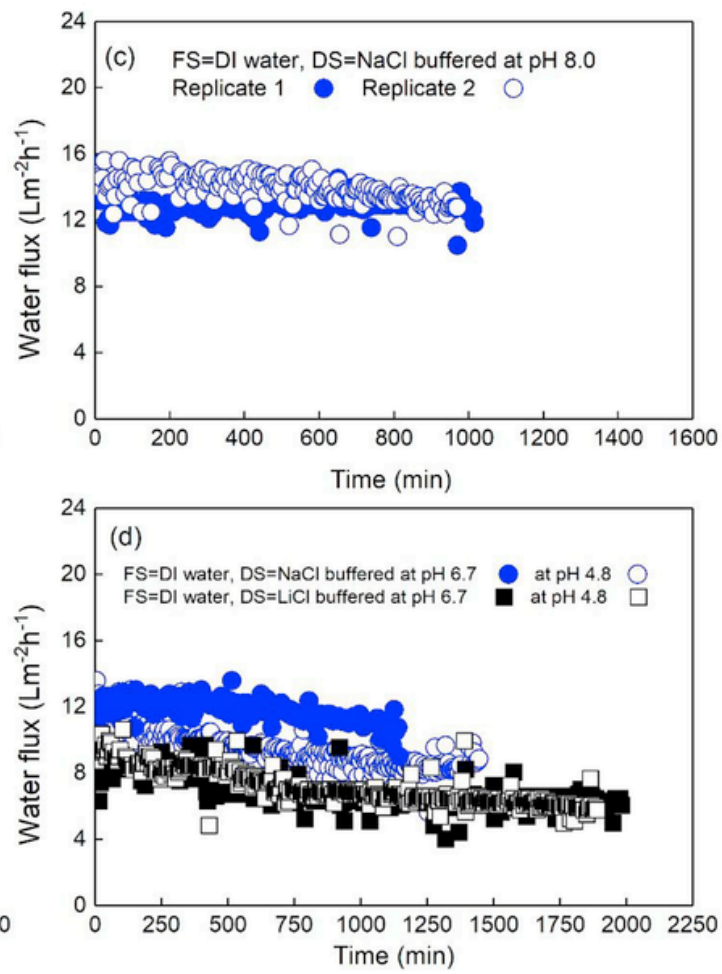

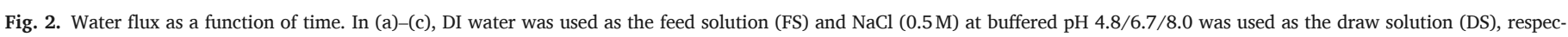

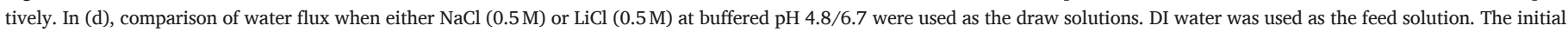
$\mathrm{pH}$ of feed solution in all experiments was $6.4 \pm 0.2$ and all experiments were conducted until $50 \%$ water recovery. 


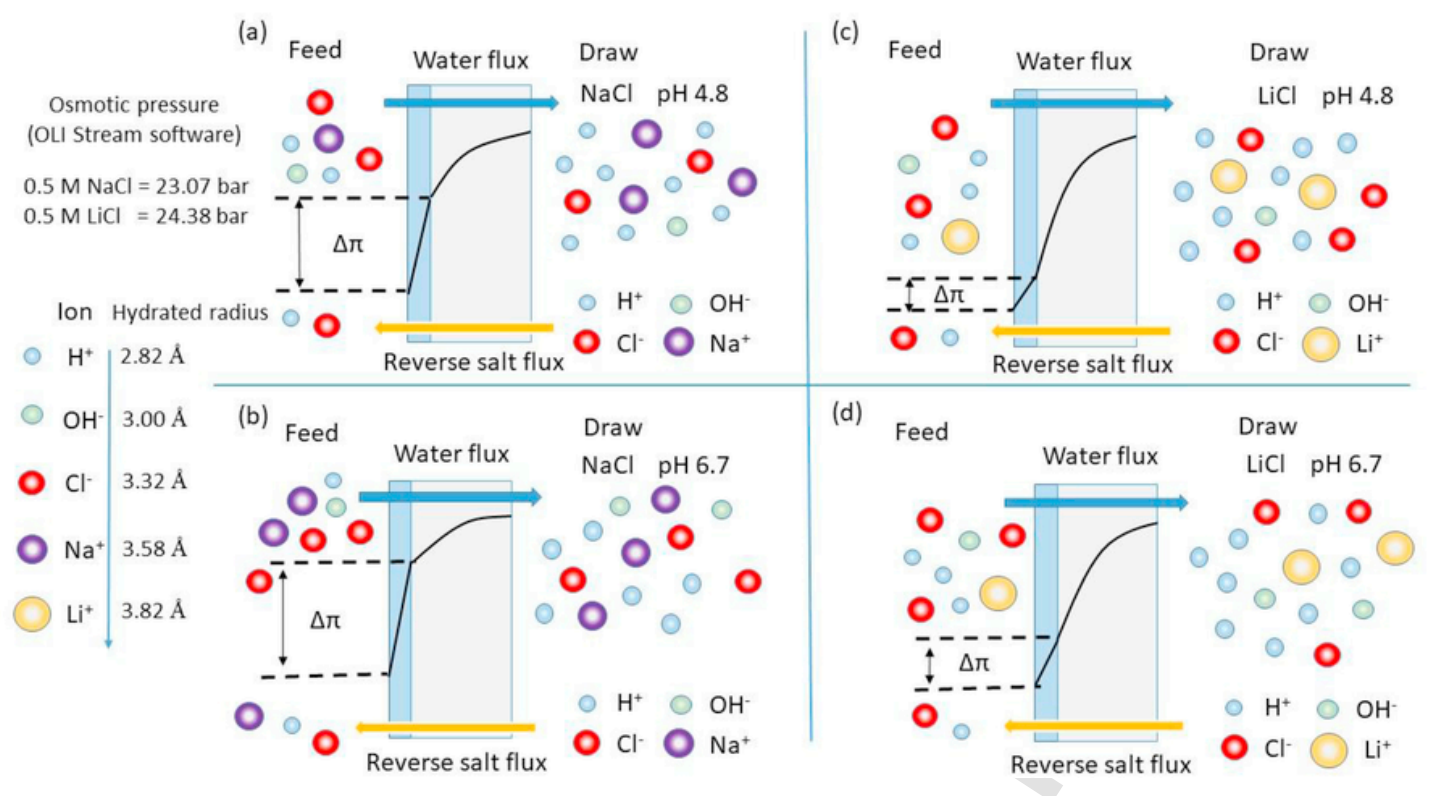

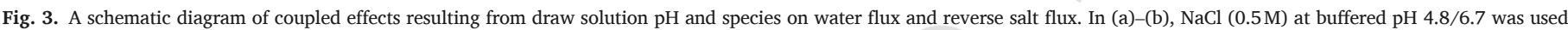

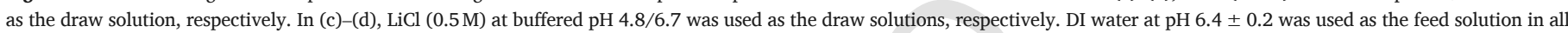
experiments. Hydrated radii data are from Ref. [36]. $\Delta \pi$ is the effective osmotic driving force.

Of a particular note, the impact of draw solution $\mathrm{pH}$ on water flux was less significant when $\mathrm{LiCl}$ was used as the draw solute (Fig. 2d). As discussed above, the transfer of $\mathrm{H}^{+}$from the draw solution to the feed at $\mathrm{pH} 4.8$ could be impacted by the diffusion of hydrated $\mathrm{Li}^{+}$(in the same way as hydrated $\mathrm{Na}^{+}$) across the membrane (Fig. 3c and d). In addition, the diffusion coefficients of alkali metals decrease as their hydrated radii increase [35]. Since $\mathrm{Li}^{+}$has a larger hydrated radius than $\mathrm{Na}^{+}$, the reverse salt flux of $\mathrm{LiCl}$ is therefore much smaller than that of $\mathrm{NaCl}$ (Fig. S3). Hence, the impact of draw solution $\mathrm{pH}$ on water flux was negligible when $\mathrm{LiCl}$ was used as the draw solute (Fig. 2d).

\subsection{Reverse salt flux selectivity}

$\mathrm{LiCl}$ had a higher reverse salt flux selectivity than $\mathrm{NaCl}$ in this study (Fig. 4 and Fig. S3). Despite a slightly lower water flux because of a more severe dilutive ICP, $\mathrm{LiCl}$ had a much lower reverse salt flux than that of $\mathrm{NaCl}$. As a result, the higher reverse salt flux selectivity of $\mathrm{LiCl}$ was observed in comparison to $\mathrm{NaCl}$. It is interesting to note that when $\mathrm{LiCl}$ was used as the draw solute, $\mathrm{pH}$ had a more significant impact on

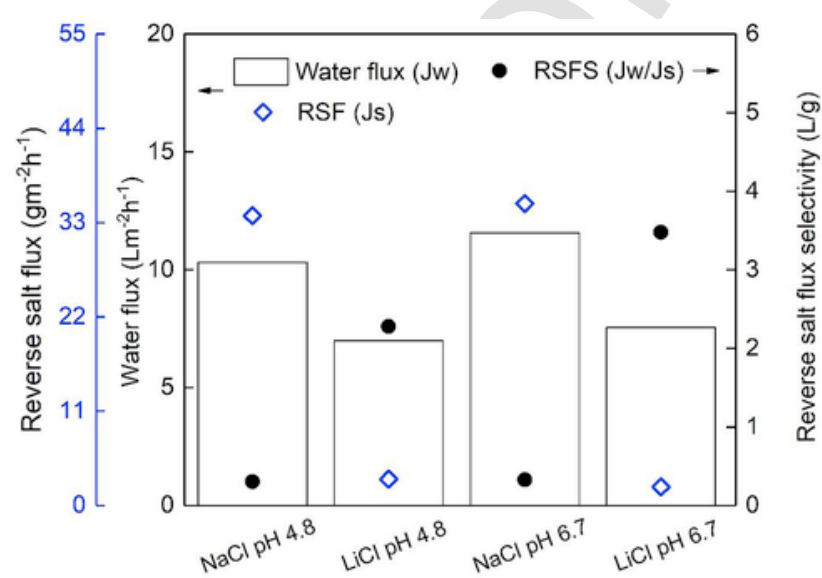

Fig. 4. Average water flux, reverse salt flux (RSF) and reverse salt flux selectivity (RSFS) of two draw solutions at two $\mathrm{pH}$ gradients. Experimental conditions: DI water was used as the feed solution; $\mathrm{NaCl}(0.5 \mathrm{M})$ or $\mathrm{LiCl}(0.5 \mathrm{M})$ at buffered $\mathrm{pH} 4.8 / 6.7$ was used as the draw solution. reverse salt flux selectivity (Fig. 4). This observed impact was in contrast to that on water flux as discussed in section 3.1. It was likely due to the very small reverse salt flux of $\mathrm{LiCl}$, where even a small change in water flux caused by the variable $\mathrm{pH}$ could lead to a noticeable change in reverse salt flux selectivity. On the other hand, the draw solution $\mathrm{pH}$ affected both the water and reverse salt flux to a similar magnitude when $\mathrm{NaCl}$ was used as the draw solute.

\subsection{Rejection of TrOCs by FO}

\subsubsection{Role of electrostatic interaction}

Results in Fig. 5 show that average rejection for charged TrOCs by FO (negatively charged compounds: $86.7 \pm 8.6 \%$; positively charged compounds: $86.9 \pm 7.6 \%$ ) were marginally better than that of neutral TrOCs $(84.4 \pm 6.8 \%)$. The difference in rejection between charged and neutral TrOCs was discernible but not as significant as previously reported with NF membranes [20]. When a molecule attained a charge, electrostatic interaction could be a major rejection mechanism. An alternative view is to consider the hydrated size of the molecule which is larger than the neutral state of the compound. Electrostatic interaction or the hydrated size can be expressed by the Debye length which is governed by the solution ionic strength [20]. Unlike a NF system, in which the feed solution usually has a low ionic strength. FO has a high ionic strength in feed because of the back diffusion from draw solution. Therefore, the ionic strength at the membrane surface on the feed side can suppress electrostatic interaction between charged TrOCs and the membrane surface. As a result, the impact of solute charge on rejection by FO was less significant as observed in Fig. 5 compared to the previous literature on the NF process.

The results showed a little correlation between the rejections of neutral TrOCs by FO and their corresponding molecular sizes in terms of minimum projection area (MPA). MPA is the two dimensional area of the conformer projected with its circular disk. Assuming the passage of compound through FO membrane as a circular shape, MPA is supposed to be most correlated with the rejection of neutral TrOCs. Results in Fig. 5 are in contrast to the NF process, in which size exclusion plays a much more significant role in the rejection of neutral TrOCs [37]. Hence, these results suggest that size exclusion was not a prevalent rejection mechanism in this study and other phenomenon such as adsorp- 


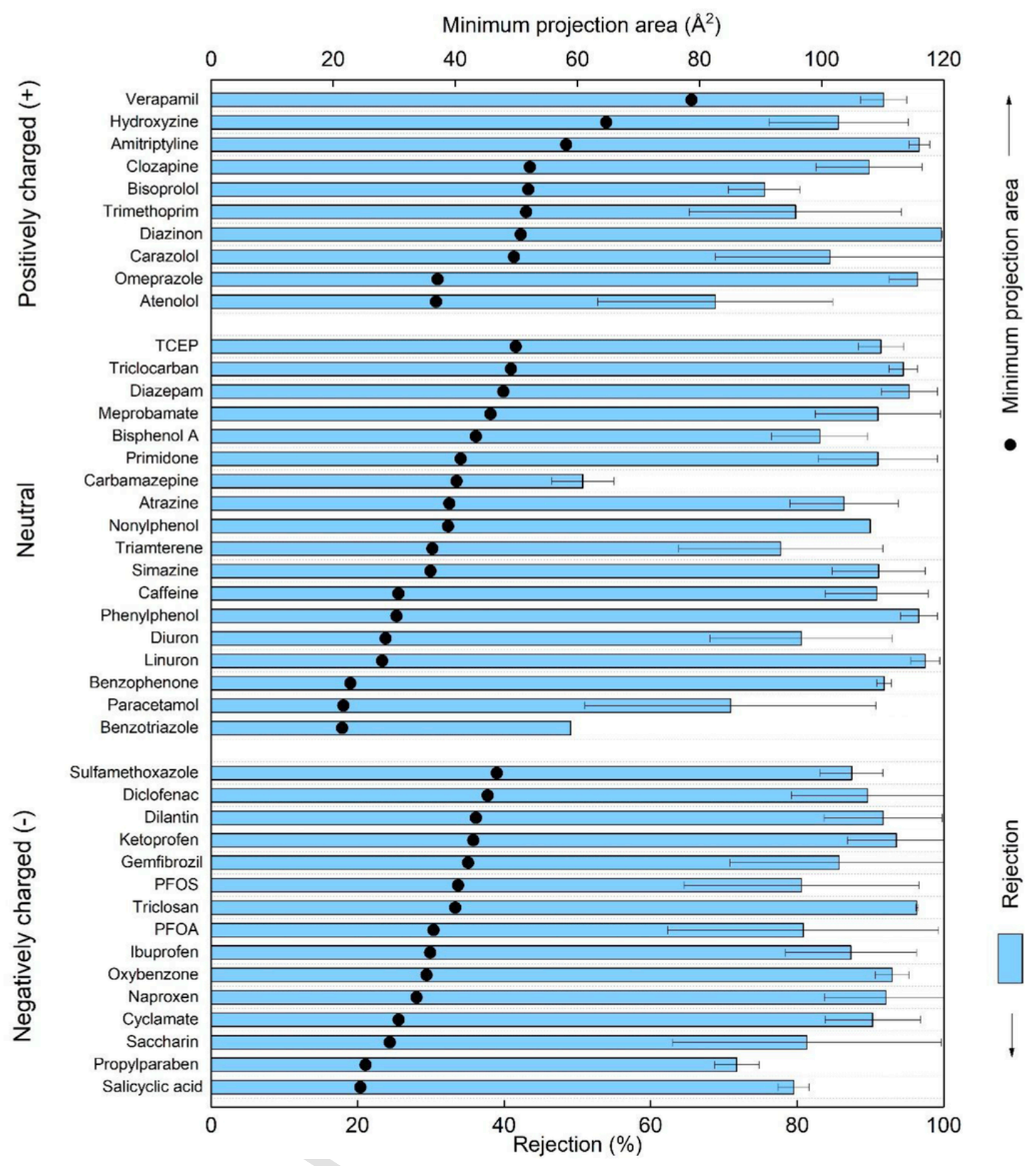

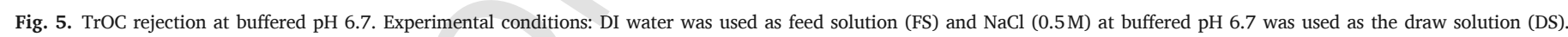

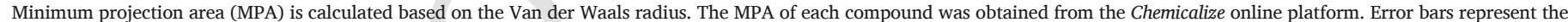
difference of two replicate measurements.

tion or dipolar interaction likely influenced the transport of TrOCs through FO membrane. For examples, benzophenone ( $\log \mathrm{D}=3.43$ ) and phenylphenol ( $\log \mathrm{D}=3.31)$ are small in sizes but are also hydrophobic $(\log \mathrm{D}>3$ ). Thus, adsorption was an additional removal mechanism, leading to relatively high observed rejection values, particularly when a limited feed volume was applied in this study. On the other hand, carbamazepine has a large MPA, but was not well rejected by FO. A plausible explanation for this observation was the high dipole moment of carbamazepine (3.6 Debye [38]), which facilitated dipolar interactions with the membrane surface [39]. In other words, due to the dipolar interaction, carbamazepine orientated toward the membrane pore, resulting in a lower rejection [40].

\subsubsection{Role of compound speciation}

Due to the bidirectional transport of proton across the membrane, $\mathrm{pH}$ in the feed solution (and thus the speciation of ionisable TrOCs) could be influenced by a pH gradient between the feed and draw solution. Hence, higher rejections were observed when TrOCs became either negatively or positively charged compared to their neutral forms because of the electrostatic interaction (Fig. 6). For example, the rejection of triclosan ( $\mathrm{pKa}=7.68$ ) increased from $47.8 \%$ (neutral) to 96.3 and $96.1 \%$ when it became negatively charged in buffered draw solutions at $\mathrm{pH} 6.7$ and 8.0, respectively. On the other hand, the rejection of triamterene ( $\mathrm{pKa}=6.2$ ) decreased by $8.8 \%$ and $6.4 \%$ when it transformed from positively charged $\mathrm{(pH} 4.8)$ to a neutral form $(\mathrm{pH} 6.7$ and 8.0), respectively. In particular, $\mathrm{pH} 6.7$ showed a lower rejection than $\mathrm{pH} 8.0$ when compounds (propylparaben and dilantin) were both negatively charged at these two $\mathrm{pH}$ values. As discussed in section 3.1, since the feed solution ionic strength decreased from $\mathrm{pH} 6.7$ to $\mathrm{pH} 8.0$ due to the increasing reverse salt flux (Fig. S1), electrostatic repulsion at $\mathrm{pH}$ 8.0 became a more prevalent rejection mechanism, leading to a higher rejection. 

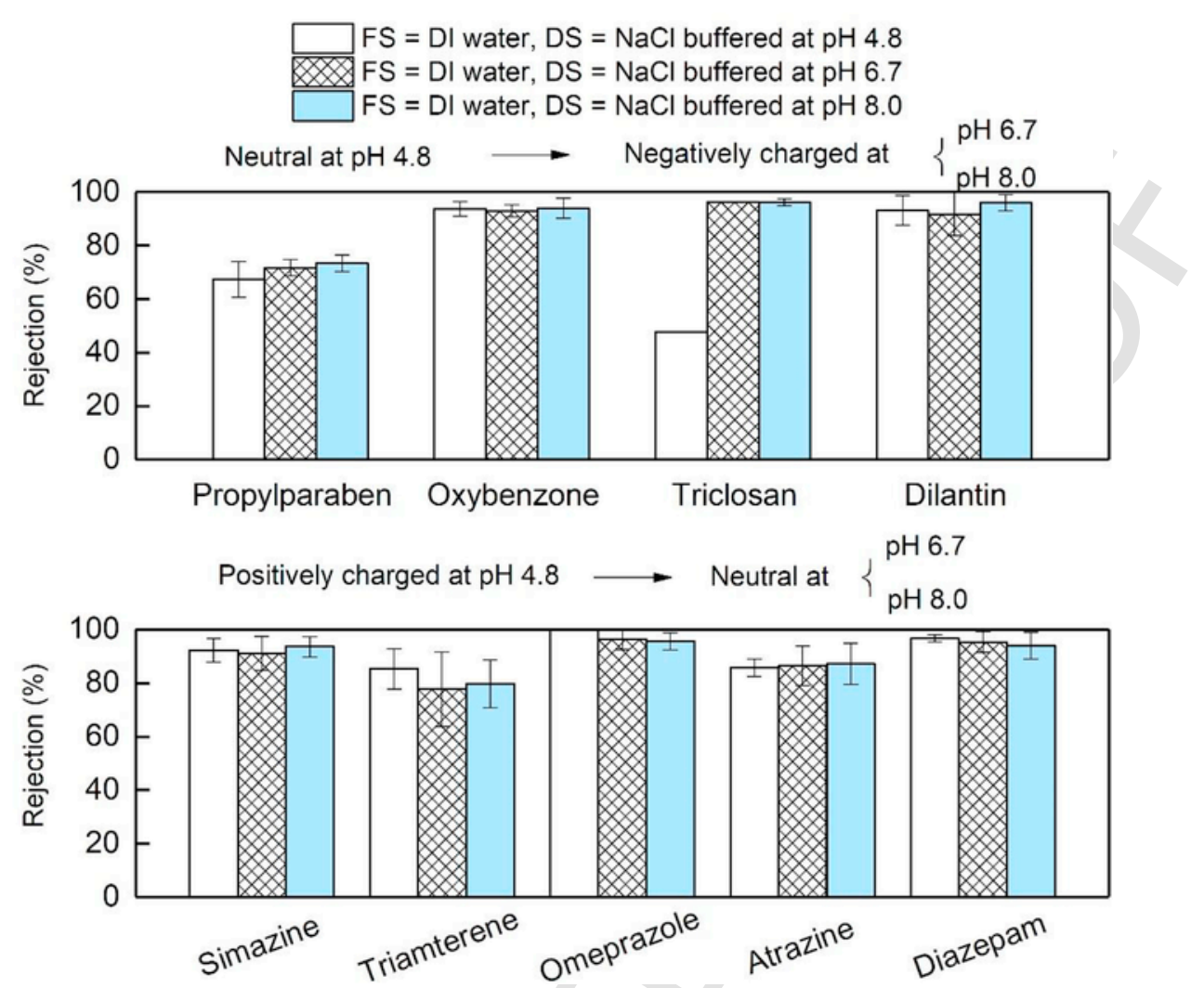

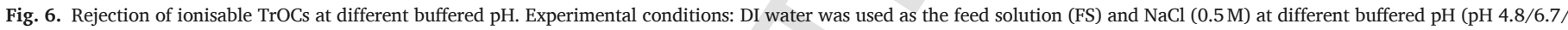
8.0) was used as the draw solutions (DS), respectively. Error bars represent the difference of two replicate measurements.

\subsubsection{Role of draw solute species}

Using $\mathrm{LiCl}$ as the draw solute resulted in slightly higher rejections of most TrOCs compared to $\mathrm{NaCl}$ (Fig. 7), which showed the data for 28 TrOCs with the discernible rejection difference between these two draw solutes. As noted in section 3.2, the reverse salt flux of $\mathrm{LiCl}$ was less than that of $\mathrm{NaCl}$ at two $\mathrm{pH}$ gradients. Ionic strength of the feed immediately at the membrane was therefore expected to be lower than $\mathrm{NaCl}$. A lower ionic strength could possibly lead to a stronger electrostatic interaction between charged TrOCs and the negatively charged membrane surface, resulting in a higher rejection. On the other hand, ionic strength could also influence the charge layer within the membrane pore or the effective membrane pore size. In other words, at a lower ionic strength, the double layer could extend further, resulting in a smaller effective pore size [17]. As a result, the effect of the lower ionic strength on the feed side was also observed for several neutral TrOCs when $\mathrm{LiCl}$ was used as the draw solute (Fig. 7).

\subsection{Rejection of TrOCs with the presence of fouling}

\subsubsection{Impact of membrane fouling on water flux}

The presence of foulants in the feed solution was a significant factor in the determination of the permeate flux. The corresponding flux declines were $70 \%$ for fouled membrane and $19 \%$ for clean membrane at $50 \%$ water recovery, respectively (Fig. 8). The gradual flux decline in DI water was due to the diminishing osmotic gradient caused by the reverse draw solute diffusion. Two instinct fouling stages were observed, possibly related to two different fouling mechanisms. A sharp drop in permeate flux was observed within the first $10 \mathrm{~h}$ of each filtration experiment. This initial rapid fouling stage can be likely attributed to the development of a fouling cake layer on the membrane surface. After $10 \mathrm{~h}$ of filtration, the rate of flux gradually became stable until the end of the experiment, which was possibly due to the thickening and compaction of the fouling layer. Similar water flux decline profiles were reported in our previous study [41].

\subsubsection{Membrane fouling characterization}

Results from LC-OCD analysis indicate that low molecular weight neutrals accounted for most ( $>70 \%$ ) of the dissolved organics in municipal sewage (Fig. 9a). Despite a high fraction of low molecular weight neutrals in municipal sewage, the organic removal by the FO process was $97.2 \%$ as indicated by a small peak of low molecular weight neutrals in the FO permeate (Fig. 9b). Although the water recovery was $50 \%$, the accumulation of other fractions except low molecular weight neutrals were negligible in the FO concentrate. Thus, it is likely that almost all low molecular weight neutrals retained by the FO process had deposited on the membrane surface to form a cake layer, resulting in a considerable flux decline as previously discussed in section 3.1. This cake layer on the membrane surface was confirmed by SEM-EDX analysis (Fig. S4). In addition, the cake layer had a significant impact on the reverse salt flux demonstrated by Fig. S5.

\subsubsection{Impact of fouling on TrOCs rejection}

The cake layer on the membrane surface could result in variable TrOCs rejection. Higher rejections by the fouled FO membrane were observed for 32 out of 43 TrOCs investigated in this study when it was compared to that under clean no-fouling conditions (Fig. 10). These observations could be attributed to the additional filtration effect by the cake layer and possibly pore blocking. As discussed in 3.4.1, the fouling layer consisted of mostly low molecular weight neutrals (molecular weight of approximate $350 \mathrm{~g} / \mathrm{mol}$ ), thus penetration of TrOCs through the cake layer to the membrane pore were negligible. These findings were consistent with those previously reported by Xie et al. [22], that the rejection was enhanced at a low initial permeate flux associated 


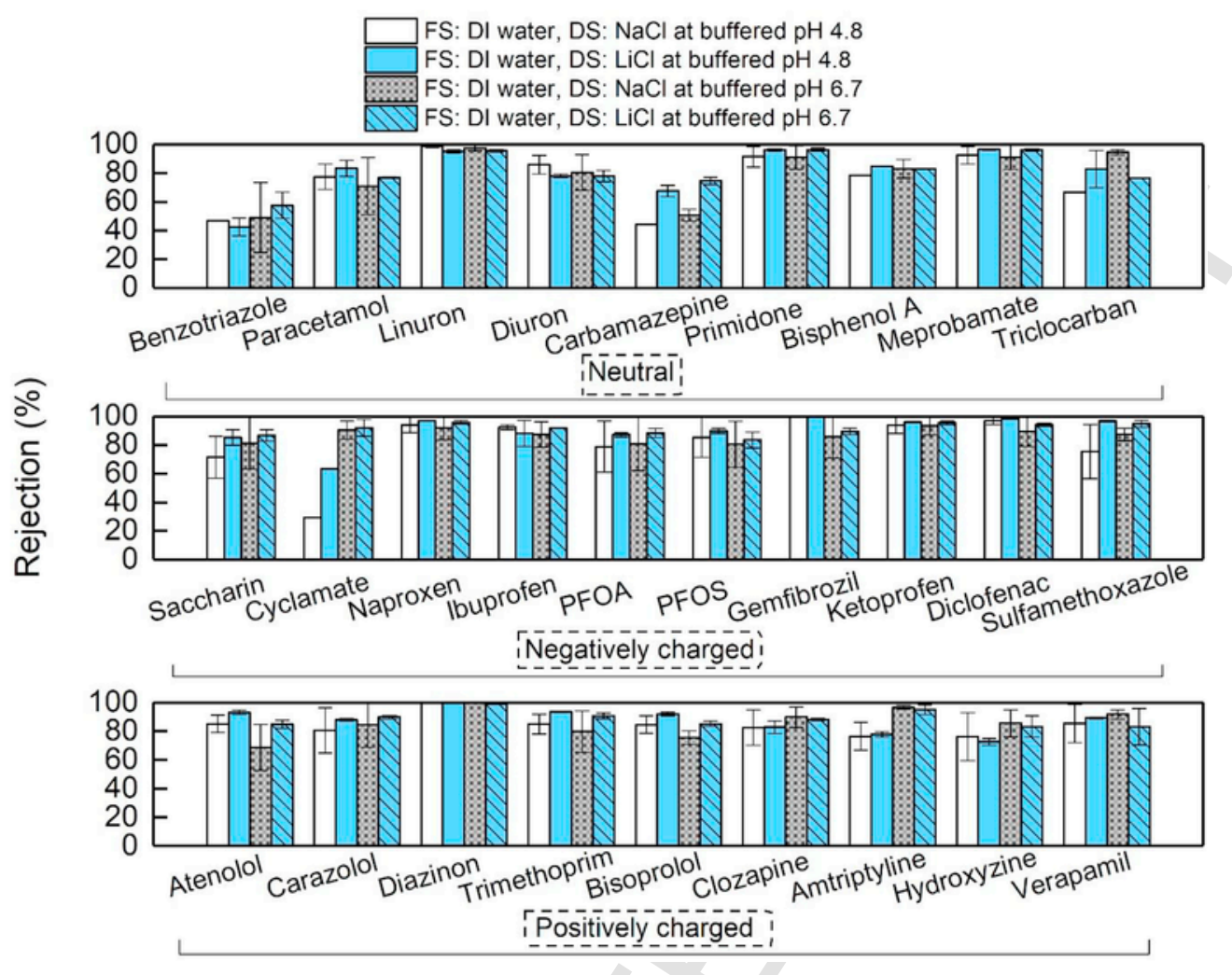

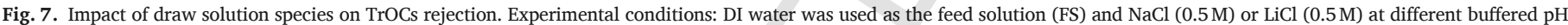
( $\mathrm{pH}$ 4.8/6.7) was used as the draw solutions (DS), respectively. Error bars represent the difference of two replicate measurements.

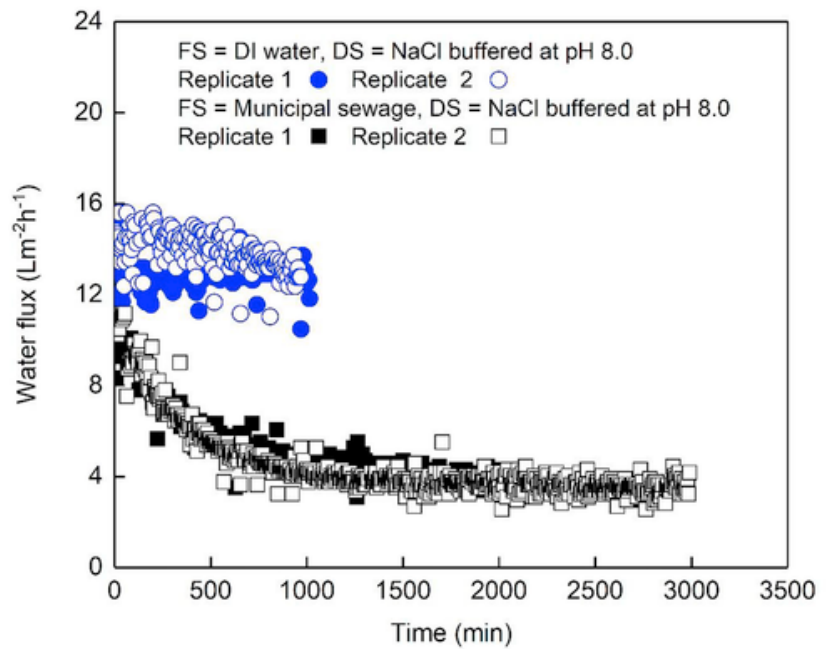

Fig. 8. Impact of fouling on the water flux: DI water or municipal sewage was used as the feed solution (FS), respectively. $\mathrm{NaCl}(0.5 \mathrm{M})$ at buffered $\mathrm{pH} 8.0$ was used as the draw solution (DS). The initial $\mathrm{pH}$ of feed solution in duplicate experiments was $6.4 \pm 0.2$ and duplicate experiments were conducted until $50 \%$ water recovery.

with a fouled membrane. It is noteworthy that several neutral compounds including carbamazepine and triclocarban exhibited lower rejections at the presence of fouling (Fig. 10). The lower rejections for neutral compounds were likely attributed to a cake-enhanced concentration polarisation effect as steric hindrance is probably the main rejection mechanism for neutral compounds. On the other hand, similar to the findings in the previous section 3.3.1, rejection behaviors exhibited no correlation with molecular size of compound (i.e. MPA) regardless of the presence of a fouling layer.

\section{Conclusions}

Results from this study indicate that draw solution chemistry (i.e. $\mathrm{pH}$ and draw solute type) could induce discernible impacts on both water flux and TrOC rejection. The impact on TrOC rejection was further interfered by the membrane fouling. Due to the bidirectional transport in the FO process, $\mathrm{pH}$ of the draw solution and feed solution were interrelated. As a result, the draw solution $\mathrm{pH}$ influenced the speciation of ionisable TrOCs in the feed solution and their rejection mechanisms by FO. Electrostatic interaction other than size exclusion was identified as the prevalent rejection mechanism for the clean membrane, which could also be explained by a poor correlation between rejections and molecular sizes of the 43 TrOCs. Compared to $\mathrm{NaCl}, \mathrm{LiCl}$ as the draw solution showed slightly higher rejections for most selected TrOCs. LiCl had a much lower reverse salt flux than $\mathrm{NaCl}$ because of a larger hydrated radius of $\mathrm{Li}^{+}$. Therefore, a lower ionic strength in the feed side and within the membrane pore caused a stronger electrostatic interaction. On the other hand, low molecular weight neutrals in municipal sewage mainly formed a fouling cake layer. This cake layer attributed to an increase in TrOCs rejection because of the severe pore blockage. However, a decrease in the rejection for several neutral TrOCs was also observed and this was likely due to the cake-enhanced concentration polarisation effect.

\section{Acknowledgement}

Lei Zheng would like to thank the Chinese Scholarship Council, University of Wollongong and University of Technology Sydney for Ph.D. scholarship support. 


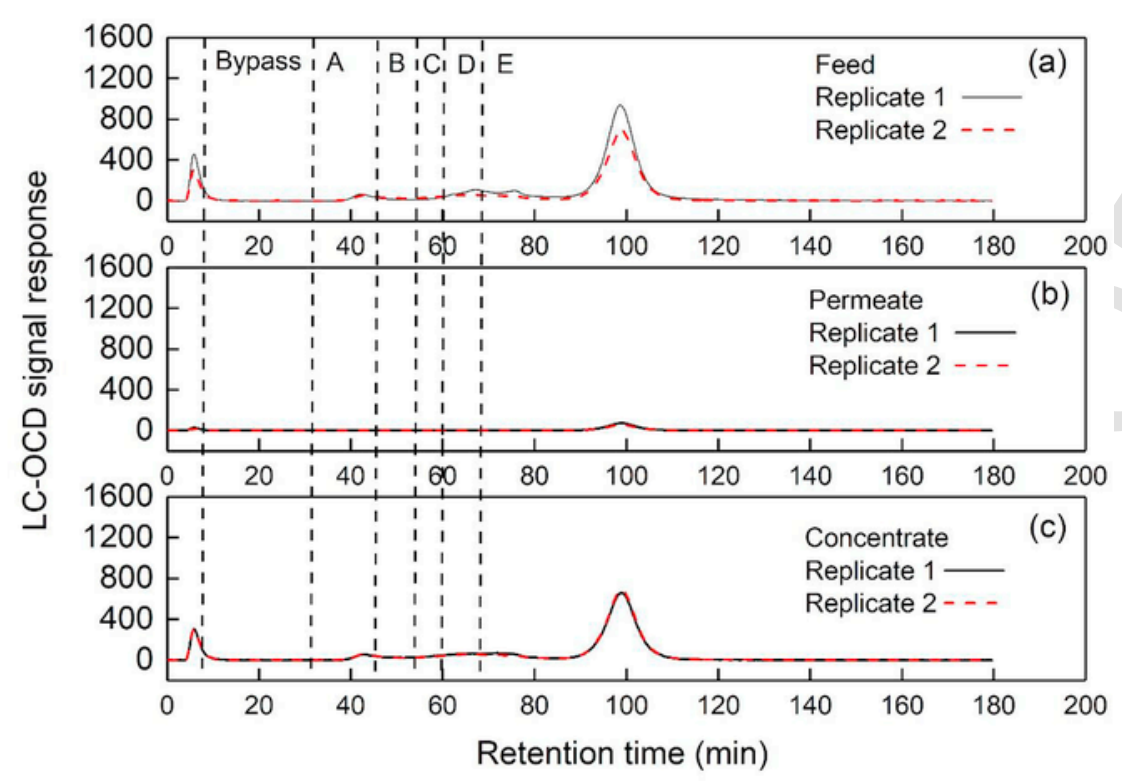

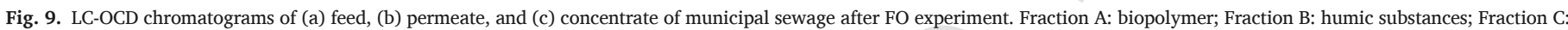
building blocks; Fraction D: low molecular weight acids; Fraction E: low molecular weight neutrals. The experiments were conducted in duplicate.
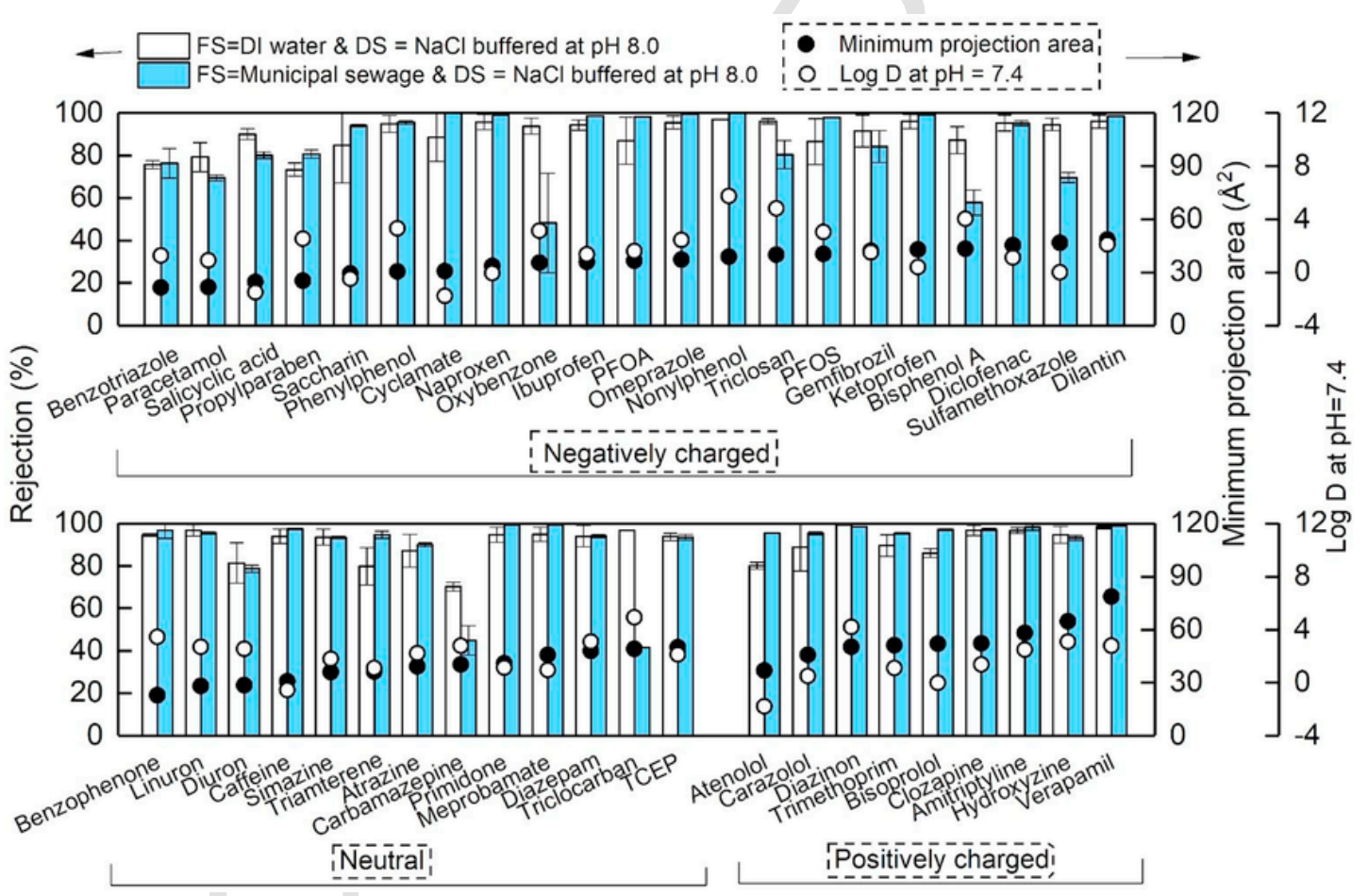

\section{'Neutrāi!}

L Ṕositivēly chärged

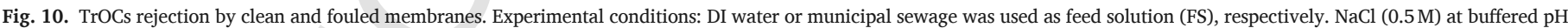
8.0 was used as the draw solution (DS). Error bars represent the difference of two replicate measurements.

\section{Appendix A. Supplementary data}

Supplementary data to this article can be found online at https:// doi.org/10.1016/j.memsci.2019.117184.

\section{References}

[1] S. Lee, C. Boo, M. Elimelech, S. Hong, Comparison of fouling behavior in forward osmosis (FO) and reverse osmosis (RO), J. Membr. Sci. 365 (2010) 34-39.

[2] D.L. Shaffer, J.R. Werber, H. Jaramillo, S. Lin, M. Elimelech, Forward osmosis: where are we now?, Desalination 356 (2015) 271-284.
[3] Y. Yang, H. Song, Z. He, Mitigation of solute buildup by using a biodegradable and reusable polyelectrolyte as a draw solute in an osmotic membrane bioreactor, Environ. Sci.: Water Res. Technol. 5 (2019) 19-27.

[4] G. Gwak, D.I. Kim, S. Hong, New industrial application of forward osmosis (FO): precious metal recovery from printed circuit board (PCB) plant wastewater, J. Membr. Sci. 552 (2018) 234-242.

[5] S. Wu, S. Zou, G. Liang, G. Qian, Z. He, Enhancing recovery of magnesium as struvite from landfill leachate by pretreatment of calcium with simultaneous reduction of liquid volume via forward osmosis, Sci. Total Environ. 610-611 (2018) 137-146.

[6] G. Chen, Z. Wang, L.D. Nghiem, X.-M. Li, M. Xie, B. Zhao, M. Zhang, J. Song, T. He, Treatment of shale gas drilling flowback fluids (SGDFs) by forward osmosis: membrane fouling and mitigation, Desalination 366 (2015) 113-120.

[7] B.D. Coday, P. Xu, E.G. Beaudry, J. Herron, K. Lampi, N.T. Hancock, T.Y. Cath, The sweet spot of forward osmosis: treatment of produced water, drilling waste- 
water, and other complex and difficult liquid streams, Desalination 333 (2014) 23-35.

[8] N.C. Nguyen, H.T. Nguyen, S.-T. Ho, S.-S. Chen, H.H. Ngo, W. Guo, S.S. Ray, H.-T. Hsu, Exploring high charge of phosphate as new draw solute in a forward osmosis-membrane distillation hybrid system for concentrating high-nutrient sludge, Sci. Total Environ. 557-558 (2016) 44-50.

[9] S. Liyanaarachchi, V. Jegatheesan, I. Obagbemi, S. Muthukumaran, L. Shu, Effect of feed temperature and membrane orientation on pre-treatment sludge volume reduction through forward osmosis, Desalination Water Treat. 54 (2015) 838-844.

[10] Y. Luo, W. Guo, H.H. Ngo, L.D. Nghiem, F.I. Hai, J. Zhang, S. Liang, X.C. Wang, A review on the occurrence of micropollutants in the aquatic environment and their fate and removal during wastewater treatment, Sci. Total Environ. 473-474 (2014) 619-641.

[11] P.E. Stackelberg, E.T. Furlong, M.T. Meyer, S.D. Zaugg, A.K. Henderson, D.B. Reissman, Persistence of pharmaceutical compounds and other organic wastewater contaminants in a conventional drinking-water-treatment plant, Sci. Total Environ. 329 (2004) 99-113.

[12] J. Garcia-Ivars, L. Martella, M. Massella, C. Carbonell-Alcaina, M.-I. Alcaina-Miranda, M.-I. Iborra-Clar, Nanofiltration as tertiary treatment method for removing trace pharmaceutically active compounds in wastewater from wastewater treatment plants, Water Res. 125 (2017) 360-373.

[13] T. Fujioka, S.J. Khan, J.A. McDonald, L.D. Nghiem, Rejection of trace organic chemicals by a hollow fibre cellulose triacetate reverse osmosis membrane, Desalination 368 (2015) 69-75.

[14] K.C. Wijekoon, F.I. Hai, J. Kang, W.E. Price, T.Y. Cath, L.D. Nghiem, Rejection and fate of trace organic compounds (TrOCs) during membrane distillation, J. Membr. Sci. 453 (2014) 636-642.

[15] X. Wang, J. Zhang, V.W.C. Chang, Q. She, C.Y. Tang, Removal of cytostatic drugs from wastewater by an anaerobic osmotic membrane bioreactor, Chem. Eng. J. 339 (2018) 153-161.

[16] M. Xie, W. Luo, H. Guo, L.D. Nghiem, C.Y. Tang, S.R. Gray, Trace organic contaminant rejection by aquaporin forward osmosis membrane: transport mechanisms and membrane stability, Water Res. 132 (2018) 90-98.

[17] M. Sauchelli, G. Pellegrino, A. D'Haese, I. Rodríguez-Roda, W. Gernjak, Transport of trace organic compounds through novel forward osmosis membranes: role of membrane properties and the draw solution, Water Res. 141 (2018) 65-73.

[18] J. Xu, T.N. Tran, H. Lin, N. Dai, Removal of disinfection byproducts in forward osmosis for wastewater recycling, J. Membr. Sci. 564 (2018) 352-360.

[19] R.W. Holloway, A. Achilli, T.Y. Cath, The osmotic membrane bioreactor: a critical review, Environ. Sci.: Water Res. Technol. 1 (2015) 581-605.

[20] L.D. Nghiem, A.I. Schäfer, M. Elimelech, Role of electrostatic interactions in the retention of pharmaceutically active contaminants by a loose nanofiltration membrane, J. Membr. Sci. 286 (2006) 52-59.

[21] M. Xie, L.D. Nghiem, W.E. Price, M. Elimelech, Impact of humic acid fouling on membrane performance and transport of pharmaceutically active compounds in forward osmosis, Water Res. 47 (2013) 4567-4575.

[22] M. Xie, L.D. Nghiem, W.E. Price, M. Elimelech, Impact of organic and colloidal fouling on trace organic contaminant rejection by forward osmosis: role of initial permeate flux, Desalination 336 (2014) 146-152.

[23] X. Jin, J. Shan, C. Wang, J. Wei, C.Y. Tang, Rejection of pharmaceuticals by forward osmosis membranes, J. Hazard Mater. 227-228 (2012) 55-61.
[24] M. Xie, W.E. Price, L.D. Nghiem, Rejection of pharmaceutically active compounds by forward osmosis: role of solution $\mathrm{pH}$ and membrane orientation, Separ. Purif. Technol. 93 (2012) 107-114.

[25] S. Zhu, M. Li, M. Gamal El-Din, The roles of $\mathrm{pH}$ and draw solute on forward osmosis process treating aqueous naphthenic acids, J. Membr. Sci. 549 (2018) 456-465.

[26] M. Xie, L.D. Nghiem, W.E. Price, M. Elimelech, Comparison of the removal of hydrophobic trace organic contaminants by forward osmosis and reverse osmosis, Water Res. 46 (2012) 2683-2692.

[27] C. Kim, S. Lee, H.K. Shon, M. Elimelech, S. Hong, Boron transport in forward osmosis: measurements, mechanisms, and comparison with reverse osmosis, J. Membr. Sci. 419-420 (2012) 42-48.

[28] Y. Kim, S. Li, L. Chekli, Y.C. Woo, C.-H. Wei, S. Phuntsho, N. Ghaffour, T. Leiknes, H.K. Shon, Assessing the removal of organic micro-pollutants from anaerobic membrane bioreactor effluent by fertilizer-drawn forward osmosis, J. Membr. Sci. 533 (2017) 84-95.

[29] Y.-N. Wang, W. Li, R. Wang, C.Y. Tang, Enhancing boron rejection in FO using alkaline draw solutions, Water Res. 118 (2017) 20-25.

[30] D.A. Eaton, S.L. Clesceri, E.A. Greenberg, Standard Methods for Examination of Water \& Wastewater, 23rd ed, American Public Health Association, 2005.

[31] S.A. Huber, A. Balz, M. Abert, W. Pronk, Characterisation of aquatic humic and non-humic matter with size-exclusion chromatography - organic carbon detection - organic nitrogen detection (LC-OCD-OND), Water Res. 45 (2011) 879-885.

[32] N. Tadkaew, F.I. Hai, J.A. McDonald, S.J. Khan, L.D. Nghiem, Removal of trace organics by MBR treatment: the role of molecular properties, Water Res. 45 (2011) 2439-2451.

[33] J.A. McDonald, N.B. Harden, L.D. Nghiem, S.J. Khan, Analysis of N-nitrosamines in water by isotope dilution gas chromatography-electron ionisation tandem mass spectrometry, Talanta 99 (2012) 146-154.

[34] J.-J. Qin, S. Chen, M.H. Oo, K.A. Kekre, E.R. Cornelissen, C.J. Ruiken, Experimental studies and modeling on concentration polarization in forward osmosis, Water Sci. Technol. 61 (2010) 2897-2904.

[35] M. Ersöz, Diffusion and selective transport of alkali cations on cation-exchange membrane, Separ. Sci. Technol. 30 (1995) 3523-3533.

[36] E.R. Nightingale, Phenomenological theory of ion solvation. Effective radii of hydrated ions, J. Phys. Chem. 63 (1959) 1381-1387.

[37] T. Fujioka, S.J. Khan, J.A. McDonald, L.D. Nghiem, Rejection of trace organic chemicals by a nanofiltration membrane: the role of molecular properties and effects of caustic cleaning, Environ. Sci.: Water Res. Technol. 1 (2015) 846-854.

[38] Hyperchem, Release 7.0 for Windows, Molecular Modeling System, Hypercube Inc., Gainesville, FL, 2002.

[39] B. Van der Bruggen, J. Schaep, D. Wilms, C. Vandecasteele, Influence of molecular size, polarity and charge on the retention of organic molecules by nanofiltration, $\mathrm{J}$. Membr. Sci. 156 (1999) 29-41.

[40] S. Darvishmanesh, J. Vanneste, E. Tocci, J.C. Jansen, F. Tasselli, J. Degrève, E. Drioli, B. Van der Bruggen, Physicochemical characterization of solute retention in solvent resistant nanofiltration: the effect of solute size, polarity, dipole moment, and solubility parameter, J. Phys. Chem. B 115 (2011) 14507-14517.

[41] L. Zheng, W.E. Price, L.D. Nghiem, Effects of Fouling on Separation Performance by Forward Osmosis: the Role of Specific Organic Foulants, Environmental Science and Pollution Research, 2018. 